\title{
Effects of Socio-Cultural Factors on Consumer Choice of Commercial Banks: A Case of Kenya Commercial Bank in Nakuru Town
}

\section{David Kipngetich Chepkangor, Elias Kimutai Rotich, Quinter Omware}

DepartmentofEducationandExternalStudies,UniversityofNairobi,Nairobi,Kenya

\section{Emailaddress:}

dchepkangor@gmail.com (D. K. Chepkangor), rotich.elias@yahoo.com (E. K. Rotich), qokeyo@gmail.com (Q. Omware)

\section{To cite this article:}

David Kipngetich Chepkangor, Elias Kimutai Rotich, Quinter Omware. Effects of Socio-Cultural Factors on Consumer Choice of Commercial Banks: A Case of Kenya Commercial Bank in Nakuru Town. Journal of Finance and Accounting. Vol. 3, No. 1, 2015, pp. 1-9. doi: 10.11648/j.jfa.20150301.11

\begin{abstract}
Customer choice of bank is an important element of banking strategy in today's increasingly competitive environment. Bank management must identify and improve upon factors that can increase customer retention. There are factors that influence customer choice of banks as customer still shift from one bank to another and since these factors are several and varied. Examples of such factors are the socio-cultural factors. This study aims to investigate the influence of socio-cultural factors on consumer choice of commercial banks in Nakuru Municipality. Nakuru municipality currently has an establishment of over twenty four banks; these banks have and continue to rely on the attrition of customers from other existing banks and also sourcing for new ones in the market. The research relied on the case of Kenya Commercial Bank in Nakuru municipality. This branch was chosen based on the fact that it has been in existence in Nakuru market for a period of over twenty years and now has a large customer base. In order to collect the required data the population of the study comprised of 396 respondents on whom questionnaires were administered. Systematic random sampling was employed where by each of the tenth customer on the queue was given a questionnaire to complete and return. The Questionnaire was piloted so as to improve its validity. The collected data was coded and analyzed by the aid of Statistical Package for Social Scientists and Microsoft excels computer software and presented in tables and a narrative summary. From the findings, consumer choice of a bank is affected by socio-cultural factors. Culture, sub culture, and group's influence consumer choice of a bank with a low effect. Personality, lifestyle and family have a very low effect on consumer choice of a bank. Customer service, availability of loan and convenience also affect consumers' choice. The study recommends that socio-cultural be considered in making decisions concerned with attraction and retention of customers.
\end{abstract}

Keywords: Socio-Cultural Factors, Consumer Choice of Commercial Banks, Non-Governmental Organizations, Nakuru Town

\section{Introduction}

\subsection{Background of the Study}

A feature of the banking industry across the globe is that it is increasingly becoming turbulent and competitive, characterized by an increasing trend towards globalization, mergers, takeovers and consolidation of the banking industry. Moreover, a number of non-banking companies have entered the banking industry by offering financial products and services (Seetanah, 2007). For example Safaricom'sMPesa services and Zain's Zap s ervices that both offer mobile banking services.
This gave a myriad of options to customers in choosing banking services. As a response and that was aided by technological developments, banks attempted to build customer satisfaction by providing better products and services and at the same time reducing its operating costs. In the developing countries, the banking sector has gained greater importance in the last decade. Consequently, the growing competition in the sector forced the banks to launch new products and services more frequently. The development and modification of these products constituted to one of the most important tasks of a bank manager (Padachi , 2007). Understanding the needs, motivations and priorities of the consumers and analyzing how they select suppliers and 
products as the first crucial steps towards the improvement of consumer satisfaction (Rojid, 2007).

To match with the competition in the banking industry, marketers needed to understand consumer behavior of both their current and prospective customers. Marketers spent a great deal of time thinking about customers and their buying behavior. They needed to know who their customers are, what they think and how they feel and why they will choose a particular bank and not just any other. Consumer behavior refers to the buying behavior of final consumers-individuals and households who buy goods and services for personal consumption. Consumer behavior involves all those psychological, social and physical mannerisms of potential customers as they become aware of products, evaluates purchase, consume and tell others about the product (Kotler, 2006).

It is therefore, this behavior consumer's display when searching for, when purchasing, using, evaluating, disposing the product or the idea that they may have for the commodity and if it will satisfy their need. Consumers around the world vary tremendously in age, income, education level, and tastes. They will also buy an incredible variety of goods and services. How these diverse consumers connect with each other and with other elements of the world around them impact their choices among various products, services and companies (Gilbert A. 1995).

However, penetrating the consumer's black box (mind) was not an easy task. Often, consumers themselves may not know exactly what might influence their purchases. "Ninety-five percent of the thought, emotion, and learning (that may often drive our purchases) occur in the unconscious mind-that is, without our awareness," notes one consumer behavior expert. The central question for marketers is: How will consumers respond to various marketing efforts the company might use (Armstrong, 2006). Consumer behavior is affected by a variety of factors. These factors include; cultural factors, social factors, personal factors, and psychological factors. All these factors influence consumers' characteristics such as motivation, perception, learning, personality, and attitude (Jr.J. Paul, 1995).

In Kenya, the history of KCB dates back to 1896 when its predecessor, the National Bank of India opened an outlet in Mombasa. Eight years later in 1904, the Bank extended its operations to Nairobi, which had become the Headquarters of the expanding railway line to Uganda. The next major change in the Bank's history came in 1958. Grindlays Bank merged with the National Bank of India to form the National and Grindlays Bank.(CBK,2010)

Upon independence the Government of Kenya acquired $60 \%$ shareholding in National \&Grindlays Bank in an effort to bring banking closer to the majority of Kenyans. In 1970, the Government acquired $100 \%$ of the shares to take full control of the largest commercial bank in Kenya. National and Grindlays Bank was renamed Kenya Commercial Bank. Whatever your banking needs, KCB has the answer. The bank has over two hundred and twenty two (222) branches in Kenya and East African region, ie. Uganda, Tanzania, Sudan,
Rwanda and Burundi (and still growing), KCB take out the hassle of your day to day banking by bringing our financial services closer to you. KCB's wide range of Personal products includes savings accounts, current accounts and credit facilities. (KCB report, 2011)

In each of our branches you will find a Personal Banker ready to assist you with your banking needs, by giving you the personalized attention you need.Kenya Commercial Bank has majored in recognizing that many citizens, particularly the low-income earners; lack access to affordable banking services, the Bank operates Mobile village Banking services which takes services closer to the people. Presently, Kenya Commercial Bank has a large number of village Banking centers widely known as "KCBMtaani". The Bank has a research and development program whose principle objective is to find ways and means of providing the best financial services to everyone. It has therefore build up a training Centre "KCB leadership Centre" for training its employees. The research unit helps the Bank to achieve its business model of being market-led (Market Intelligence Bank Survey, 2006).

\subsection{Research Objectives}

This study was guided by two objectives:

$i$ To investigate the influence of cultural factors on consumers choose a bank.

ii To determine how social factors influence consumers' choice of commercial bank.

\subsection{Research Questions}

i How do cultural factors influence the manner in which consumers choose a bank?

ii How do social factors influence consumers' choice of commercial bank?

\subsection{Significance of the Study}

This study is important to various stakeholders as described under: The findings of this study will benefit to various banks in that they got to liaise with the consumers in order to establish their needs, and also look for the best ways of meeting these needs better than their competitors. The consumers will also have a heightened awareness in regard to what factors to consider when choosing a bank. The banks' top management will use the study findings in decision making to enable them to improve their services and expand their customer base. New entrants in the banking industry will also benefit from the findings on what the consumers look for in a bank. It will serve as an industry analysis to enable them to know how consumers make their choices for banks. Researchers and academicians will use these findings as a basis for future research.

\subsection{Conceptual Framework}

Figure 1 shows the relationship between the independent variables and dependent variables. Social factors and cultural factors are the independent variables while the dependent variable is the consumer choice of Banks. This conceptual 
framework hypothesizes that there is a relationship between the social factors i.e Gender, Age, level of education, marital status and the level of customer choice of banks.

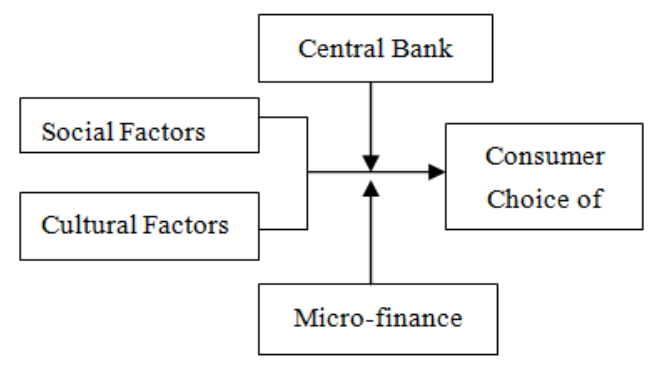

Figure 1. Conceptual Framework

\section{Literature Review}

\subsection{Social Factors and Consumer Choice of a Commercial Bank}

There are three social factors that may influence a consumer's choice of a bank namely; A person's behavior is influenced by many small groups. Groups that have a direct influence and to which a person belongs are called membership groups. In contrast, reference groups serve as direct (face-to-face) or indirect points of comparison or reference in forming a person's attitude or behavior. Marketers try to identify the reference groups of their target markets. Reference groups expose a person to new behaviors and lifestyles, influence the person's attitudes and self-concept, and create pressures to conform that may affect the person's product and brand choices (Kotler, 2006).

The importance of group influence tends to be strongest when the product is visible to others whom the buyer respects. Manufacturers of products and brands subjected to strong group influence must figure out how to reach opinion leaders that is, people within a reference group who, because of special skills, knowledge, personality, or other characteristics, exert influence on others. Consumers often are influenced by reference groups to which they do not belong. For example, an inspirational group is one to which the individual wishes to belong (Churchill, 1995).

Family members can strongly influence buyer behavior. The family is the most important consumer buying organization in society. Marketers are interested in the roles and influence of the husband, wife, and children on the purchase of different products. Husband-wife involvement varies widely by product category and by stage in the buying process. Children may also have strong influence on family buying decisions. For example, children as young as six years may influence the family car purchase decision (Churchill, 1995).

A person belongs to many groups - family, clubs, an $d$ organizations. The person's position in each group can be defined in terms of both role and status. A role consists of the activities people are expected to perform according to the persons around them. Each role carries a status reflecting the general esteem given to it by society. Consumers usually choose products appropriate to their roles and status (Kotler, 2006).

\subsection{Cultural Factors and Customer Choice of Commercial Banks}

Cultural factors include the following: Culture is the most basic cause of a person's wants and behavior. Human behavior is largely learned. Every group or society has a culture, and cultural influences on buying behavior may vary from one consumer to another depending on his/her culture. Failure to adjust to these differences can result in ineffective marketing or embarrassing mistakes. Marketers are always trying to spot cultural shifts in order to discover new products that might be wanted (Kotler, 2006).

Each culture contains smaller subcultures, or groups of people with shared value systems based on common life experiences and situations. Subcultures include nationalities, religions, racial groups and geographic regions. Many subcultures make up important market segments, and marketers in the banking industry need to design products and marketing programs tailored to their needs (Kotler, 2006).

Social classes are society's relatively permanent and ordered divisions whose members share similar values, interests, and behaviors. Social class is not only determined by income but also measured as a combination of occupation, income, education, wealth and other variables. Marketers are interested in social class because people within a given social class tend to exhibit similar buying behavior (Armstrong, 2006).

According to (Churchill, 1995), social scientists have identified the seven American social classes as upper uppers, lower uppers, upper middles, middle class, working class, upper lowers, and the lower lowers. The upper uppers class includes the social elite who live on inherited wealth. They give large sums to charity, own more than one home, and send their children to the finest schools. The lower uppers class includes people who have earned high income or wealth through exceptional ability. They are active in social and civic affairs and buy expensive homes, education, and cars. (Churchill, 1995)

The upper middles class includes professionals, independent business persons, and corporate managers who possess neither family status nor unusual wealth. They believe in education, are joiners and highly civic minded, and want the better things in life. The middle class constitutes the average-pay white-and blue-collar workers who live on the better side of town. They buy popular products to keep up with trends. The working class includes those who lead a working-class lifestyle. They depend heavily on relatives for economic and emotional support, for advice on purchases, and for assistance in times of trouble. (Churchill 1, 1995)

The upper lowers class consists of the working poor. Although their living standard is just above poverty, they strive toward a higher class. However, they often lack education and are poorly paid for unskilled work. The lower lowers class is constituted of individuals that are visibly poor, often poorly educated unskilled laborers. They are often out of 
work and some depend on public assistance. (Churchill 1, 1995)

\subsection{The Consumer Behavior Theory}

Consumer behavior refers to the buying behavior of final consumers. It is the behavior that consumers display when searching for, when purchasing, using, evaluating, disposing the product or the idea that they have for the commodity and if it will satisfy their need. The study of consumer behavior therefore seeks to understand how the consumers make decisions on how to spend their available resources in regard to purchase (Kotler, 2006). Consumer behavior is of importance to the marketers as it helps them understand why and how individuals make decisions so that they can make better marketing decisions to have a great competitive advantage at the market place (Armstrong, 2006).

Consumers make many buying decisions every day. Most large companies research consumer buying decisions deeply with an aim to find answers to questions such as what consumers buy, where they buy, how and how much they buy, when they buy, and why they buy and how they dispose what they have bought and don't need. The central question for marketers is: How do consumers respond to various marketing efforts the bank might use? The starting point is the stimulus-response model of buyer behavior (Kotler, 2006).

\begin{tabular}{|c|c|}
\hline \multicolumn{2}{|c|}{ Marketing and other stimuli } \\
\hline Marketing & Other \\
\hline Product & Economic \\
\hline Price & Technological \\
\hline Place & Political \\
\hline Promotion & Cultural \\
\hline \multicolumn{2}{|c|}{$\downarrow$} \\
\hline \multicolumn{2}{|c|}{ Buyer's black box } \\
\hline Buyer's black box & Buyer decision process \\
\hline \multicolumn{2}{|c|}{$\downarrow$} \\
\hline \multicolumn{2}{|c|}{ Buyer responses } \\
\hline \multicolumn{2}{|c|}{ Product choice } \\
\hline \multicolumn{2}{|c|}{ Brand choice } \\
\hline \multicolumn{2}{|c|}{ Dealer choice } \\
\hline \multicolumn{2}{|c|}{ Purchase timing } \\
\hline \multicolumn{2}{|c|}{ Purchase amount } \\
\hline
\end{tabular}

Source: (Kotler, 2006)

\section{Figure 2. The model of consumer behavior}

This model shows that marketing and other stimuli enter the consumer's mind and stimulate certain responses. Therefore, marketers must figure out what is in the buyer's black box (mind). The black box model assumes that observable behavior is the only valid object of study and that psychological constructs are part of an impenetrable box which should not be opened. Marketing stimuli consist of the product, price, place, and promotion. Other stimuli include major forces and events in the buyer's environment such as economic, technological, political and socio-cultural. All these inputs enter the buyer's black box, where they are turned into a set of observable buyer responses such as product choice, brand choice, dealer choice, purchase timing, and purchase amount (Kotler, 2006). .

The marketer wants to understand how the stimuli are changed into responses inside the consumer black box, which has two parts. The first part includes the buyers' characteristics that influence how he/she perceives and reacts to stimuli. The other part includes the buyers' decision process (Gary Armstrong, 2006).

The other models include economic view, passive view, cognitive view, and emotional view. The economic view model is where consumer is seen as a rational decision maker. It's the classical economic model of how individuals make decisions.

The criticisms of the view are that: for one to be rational, he should have all the information on the available products. Secondly one has to be capable of currently ranking each alternative available (John C, 1995). Passive view model depicts that consumers are basically submissive to the self-interests and promotional efforts of marketers. Consumers are perceived as impulsive and irrational purchasers ready to yield to the arms of marketers (Schoof, 1995).

However, this view fails to recognize that the consumer plays an equal if not dominant role in buying situations. Consumers sometimes seek information about product or service that satisfies the mood or emotion of the moment. Also motivation, perception, and learning serves to support that consumer are rarely objects of manipulation (Schoof, 1995). Cognitive view model portrays a consumer as a thinking problem solver. Here consumers are depicted as either receptive to or actively searching for products and services that fulfill their needs and enrich their lives. It focuses on the process by which consumers seek and evaluate information about selected brands in retail outlets. Consumers are also seen as information processors who then form preferences and ultimately arrive at purchase intentions (John C, 1995).

Marketers often prefer to think of consumers in terms of either economic or passive models. In reality, consumers relate deep feelings or emotions such as joy, fear, hope, and love with certain purchases. For example a person who misplaces a favorite fountain pen may go to great lengths to look for another despite the fact that he may have six others at hand. Consumer moods are also important to decision making because impact of where, when and whether to shop along with others (John C, 1995).

\section{Research Methodology}

\subsection{Research Design}

The study used the descriptive case study research design, employing both quantitative and qualitative approaches. According to Yin (2003) descriptive case studies are used to describe an event/ process in its natural ambit and the main objective is to answer how, who and what questions.The descriptive case study design was appropriate for this research 
as it provides an opportunity to obtain critical and practical understanding of the factors determining consumer choice of banks in Kenya commercial bank in Nakuru town. Garson (2008) argues that in a case study research, because only a few instances are normally studied, the case researcher can uncover more variables relevant to the study.

\subsection{The Target Population}

The population of interest for this study comprised of the customers of Kenya Commercial Bank branches in the central business of Nakuru town. According to KCB (strategy and new business; consumer shares survey, 2011), Kenya Commercial has a $15 \%$ of the banking market share in Nakuru town. According to the same report KCB branch Nakuru has a customer base of thirty four thousand five hundred $(34,500)$ customers which forms a target for this study. They have been categorized as follows.

Table 3.1. KCB, Nakuru Branch category of Customers

\begin{tabular}{llll}
\hline Cooperate & Salaried/white collar & $\begin{array}{l}\text { Small and micro } \\
\text { enterprises }\end{array}$ & Total \\
\hline 2,500 & 23,000 & 9,000 & 34,500 \\
\hline
\end{tabular}

Source: KCB strategy and new business - consumer shares survey (2011)

\subsection{Sampling Procedure}

Based on this and taking into account the possibility of non-response from some respondents the data shall collect from the entire sample population of 396. The target respondents were the customers who represented the selection by $\mathrm{KCB}$ as a representative sample of $\mathrm{KCB}$ customer base. The clients from the three strata were chosen based on their ability to understand the bank accounts as products from $\mathrm{KCB}$ Nakuru branches.

Shows procedures for sample selection based on three categories of consumers. Thestudy allows proportional allocation based on.

$$
\mathrm{n} i=(\mathrm{n} / \mathrm{N}) \times \mathrm{N} i
$$

Wheren $i=$ proportion in category $i$ (where $i=1,2,3$ ) Where $\mathrm{n}$ is the sample size.

$\mathrm{N} i=$ Total numberof respondents in category $i$ (where $i=$ 1,2,3)

$\mathrm{N}=$ Target population.

$\mathrm{n} 1=(396 / 34,500) \times 2,500=29$

$\mathrm{n} 2=(396 / 34,500) \times 23,000=264$

$\mathrm{n} 3=(396 / 34,500) \times 9,000=103$

Total $=396$

\subsection{Pilot Testing}

The questionnaire was pilot tested with a representative sample of KCB Flamingo Branch in Nakuru Town, which have relatively similar characteristics in setting and operating under just like Kenya Commercial Bank in Nakuru town. The results of the pilot study helped to identify necessary changes that should be effected in the questionnaire to improve the instrument prior to its administration

\subsection{Validity and Reliability Test}

Saunders (2000) contends that research is valid only if it actually studies what it set out to study and only if the findings are verifiable. In this study validity was ensured through examination of existing literature to identify conceptual dimensions and appraisal of the instrument by a panel of Customer Service Supervisors and research experts including my supervisor. Construct validity describes whether the case study gives support to the intended interpretation of the variables and in this study it will be increased through multiple sources of evidence as well as key informants reviewing the research instrument to avoid misunderstandings.

Reliability indicates the stability and consistency with which the data collection instrument measures the concept (Zikmund, 2000). In this study, the reliability of the research instrument were improved through the use of the split-half reliability procedure where the researcher administered the entire instrument to a sample of respondents during the pilot testing and were calculated using the total score for each randomly divided half i.e. odd and even numbered items of the questionnaire. A reliability coefficient between the two total scores was calculated using the Spearman-Brown prophecy tool. According to Fraenkel\&Wallen (2000) if the results produce a reliability coefficient $>=0.7$ the instrument will be considered reliable. The formula for reliability is as shown below:

$$
r e=\frac{2 r}{1+r}
$$

Where:

re - Reliability

$2 \mathrm{r}-$ correlation coefficient of 1 st half

$1+r$ - correlation coefficient of 2 nd half

The results yield a reliability coefficient of 0.698 therefore the instrument were considered reliable.

\subsection{Data Analysis}

In order to facilitate data analysis the filled up questionnaires were checked for completeness, consistency and clarity. The responses were coded by assigning a numerical value to each to make them quantitative that made it possible for the data to be entered in to the computer using the SPSS for Windows Version 10 for analysis. In order to clean up the data averages like mean and median as well as distributions like standard deviations were performed on the data sets in order to discover any anomalies and appropriate corrections. Descriptive statistics such as frequencies, percentages, median and mode was used for quantitative analysis of the data.In order to establish the influence of social-cultural factors on customer's choice of banks, descriptive statistics of frequencies, percentages, median and 
mode was used to summarize opinions of the respondents.

\section{Discussion}

\subsection{Social Factors}

Effect of social class on consumer choice of a bank was sought from the study and the findings are presented in the following table.

Table 4.1. Social Class

\begin{tabular}{lll}
\hline Ranking & Frequency & Percentage (\%) \\
\hline No effect & 0 & 0.0 \\
Very Low effect & 0 & 0.0 \\
low effect & 85 & 24.3 \\
High effect & 177 & 50.6 \\
Very high effect & 33 & 9.4 \\
Not Ranked & 55 & 15.7 \\
TOTAL & 350 & 100.0 \\
\hline
\end{tabular}

From the table 4.1 above, the data established that the percentage of the respondents who felt that social class has low effect on consumer choice of a bank constituted $24.3 \%$, those who felt that it has a high effect constituted $50.6 \%$, those who felt that it has a very high effect constituted $9.4 \%$ while $15.7 \%$ of the respondents did not rank this effect. Therefore the study concluded that a majority of the respondents felt that social class has a high effect on consumer choice of a bank.

The study wanted to establish the level of effect of groups on consumer choice of a bank and therefore he came up with the following table.

Table 4.2. Social Groups

\begin{tabular}{lll}
\hline Ranking & Frequency & Percentage (\%) \\
\hline No effect & 15 & 4.4 \\
Very Low effect & 140 & 40.0 \\
Low effect & 195 & 55.6 \\
High effect & 0 & 0.0 \\
Very high effect & 0 & 0.0 \\
Not Ranked & 0 & 0.0 \\
TOTAL & 350 & 100.0 \\
\hline
\end{tabular}

From the table 4.2 above, the data established that the percentage of the respondents who felt that groups have no effect on consumer choice of banks was $4.4 \%$, those that felt that it has a very low effect constituted $40 \%$ and those that felt that it has a low effect constituted $55.6 \%$. The data concluded that a majority of the respondents felt that groups have low effect on consumer choice of a bank.

The study also wanted to establish the effect of family on consumer choice of a bank and therefore he came up with the following table.
Table 4.3. Family Factors

\begin{tabular}{lll}
\hline Ranking & Frequency & Percentage (\%) \\
\hline No effect & 15 & 4.4 \\
Very Low effect & 125 & 35.6 \\
low effect & 210 & 60.0 \\
High effect & 0 & 0.0 \\
Very high effect & 0 & 0.0 \\
Not Ranked & 0 & 0.0 \\
TOTAL & 350 & 100.0 \\
\hline
\end{tabular}

From the above table 4.3 , the researcher established that the percentage of the respondents who felt that family has no effect on consumer choice of banks was $4.4 \%$, those that felt that it has a very low effect constituted $35.6 \%$ and those that felt that it has a low effect constituted $60 \%$. The researcher concluded that family has a low effect on consumer choice of a bank. This agrees to Kotler's argument that a person belongs to many groups - family, clubs, and organizations.

Effect of role and status of the respondent on consumer choice of a bank was sought from the study and the findings are presented in the following table.

Table 4.4. Role and Status

\begin{tabular}{lll}
\hline Ranking & Frequency & Percentage (\%) \\
\hline No effect & 0 & 0.0 \\
Very Low effect & 33 & 9.4 \\
low effect & 116 & 33.1 \\
High effect & 201 & 57.5 \\
Very high effect & 0 & 0.0 \\
Not Ranked & 0 & 0.0 \\
TOTAL & 350 & 100.0 \\
\hline
\end{tabular}

From the above table 4.4 , the study established that the percentage of the respondents who felt that role and status has a very low effect on consumer choice of a bank constituted $9.4 \%$, those that felt that it has a low effect constituted $33.1 \%$ and those that felt it has a high effect constituted $57.5 \%$. The study concluded that role and status has a high effect on consumer choice of a bank.

\subsection{Cultural Factors}

The study sought to find out the extend that cultural factors influence the manner in which consumers choose a bank based on culture, subculture that one learns from his/her current environment and the social class one interacts with. Under culture, the study wanted to establish the level of effect culture has on consumer choice of a bank and therefore he came up with the following table.

Table 4.5. Culture

\begin{tabular}{lll}
\hline Ranking & Frequency & Percentage \\
\hline No effect & 0 & 0.0 \\
Very Low effect & 105 & 30.0 \\
low effect & 201 & 57.5 \\
High effect & 0 & 0.0 \\
Very high effect & 0 & 0.0 \\
Not Ranked & 44 & 12.5 \\
TOTAL & 350 & 100.0 \\
\hline
\end{tabular}


From table 4.5, the data established that the percentage of the respondents who felt that culture has a low effect on consumer choice of banks was $57.5 \%$, those that felt that it has a very low effect constituted $30 \%$, while $12.5 \%$ of the respondents did not rank this effect. Therefore the data showed that culture has low effect on consumer choice of a bank. The study wanted to establish the effect of sub culture on consumer choice of a bank and therefore he came up with the following table.

Table 4.6. Sub Culture

\begin{tabular}{lll}
\hline Ranking & Frequency & Percentage (\%) \\
\hline No effect & 0 & 0.0 \\
Very Low effect & 70 & 20.0 \\
low effect & 232 & 66.2 \\
High effect & 0 & 0.0 \\
Very high effect & 0 & 0.0 \\
Not Ranked & 48 & 13.8 \\
TOTAL & 350 & 100.0 \\
\hline
\end{tabular}

From the above table, the data established that the percentage of the respondents who felt that sub culture has a low effect on consumer choice of banks was $66.2 \%$, those that felt that it has a very low effect constituted $20 \%$, while $13.8 \%$ of the respondents did not rank this effect. In conclusion, the researcher found out that sub culture has low effect on consumer choice of a bank.Each culture contains smaller subcultures, or groups of people with shared value systems based on common life experiences and situations. Subcultures include nationalities, religions, racial groups and geographic regions. Many subcultures make up important market segments, and marketers in the banking industry need to design products and marketing programs tailored to their needs (Kotler, 2006).

\section{Conclusions and Recommendations}

On cultural factors the study found out that culture has low effect on consumer choice of a bank. These findings do not agree with Kotler, (2006) who had argued that culture is the most basic cause of a person's wants and behavior and that culture has influence on buying behavior. However, the findings partly agree to his reasoning that consumer behavior may vary from one consumer to another depending on his/her culture. The net effect of this is that marketers are always trying to spot cultural shifts in order to discover new products that might be wanted (Kotler, 2006).Each culture contains smaller subcultures and from the data, sub culture has low effect on consumer choice of a bank. This finding strengthens Kottler's (2006) argument that each culture contains smaller subcultures, or groups of people with shared value systems based on common life experiences and situations. Subcultures include nationalities, religions, racial groups and geographic regions. Many subcultures make up important market segments, and marketers in the banking industry need to design products and marketing programs tailored to their needs but subcultures taken literary may not influence consumer's choice of a bank (Kotler, 2006).
Majority of the respondents felt that social class has a high effect on consumer choice of a bank. Social classes are society's relatively permanent and ordered divisions whose members share similar values, interests, and behaviors. Social class is not only determined by income but also measured as a combination of occupation, income, education, wealth and other variables. Marketers are interested in social class because people within a given social class tend to exhibit similar buying behavior (Armstrong, 2006), hence easily influence each other.

On social factors the data found out that a majority of the respondents felt that groups and family have low effect on consumer choice of a bank. This finding agrees with Churchill, (1995)who had argued that Consumers often are influenced by reference groups to which they do not belong. For example, an inspirational group is one to which the individual wishes to belong (Churchill, 1995). Family members can strongly influence buyer behavior. Marketers are interested in the roles and influence of the husband, wife, and children on the purchase of different products. Husband-wife involvement varies widely by product category and by stage in the buying process. Children may also have strong influence on family buying decisions. For example, children as young as six years may influence the family car purchase decision (Churchill, 1995). It also agrees to Kotler's argument that a person belongs to many groups, family, clubs, and organizations.

From the study role and status has a high effect on consumer choice of a bank. The person's position in each group can be defined in terms of both role and status. A role consists of the activities people are expected to perform according to the persons around them. Each role carries a status reflecting the general esteem given to it by society according to Kotler, Consumers usually choose products appropriate to their roles and status (Kotler, 2006).Marketers try to identify the reference groups of their target markets. Reference groups expose a person to new behaviors and lifestyles, influence the person's attitudes and self-concept, and create pressures to conform that may affect the person's product and brand choices (Kotler, 2006).

Majority of the correspondences indicated that a cultural factor has low effect on consumer choice of commercial banks. Despite this finding not agreeing with Kotler, (2006), the findings have partly agreed to his reasoning that consumer behavior may vary from one consumer to another depending on his/her culture. Therefore there is need for banks to seriously consider culture as a factor the can help them gain or maintain its customers. However low the effect may be, one needs to be conscious of its impact on its business in that this can contribute to making a profit or a loss with the same level of effect.

Social factors have also generally been rated to have low effects on consumer choice of commercial bank. This finding has agreed with Churchill, (1995) who had argued that consumers often are influenced by reference groups to which they do not belong. Family members can also strongly influence buyer behavior e.g. spouse or children. Banks therefore should consider having products that can be 
influenced by social factors bearing in mind that this same low level of effect on consumers' choice can affect at the same rate its profit performance.

To anyone interested in looking further into this topic, the researcher would suggest that a survey of different banks in the country should be carried out instead of focusing on the branches of the one bank. This will enable the other researchers to collect information from customers of different banks.

\section{References}

[1] Abratt, R., Russell, J. (1999). Relationship Marketing in Private Banking South AfricaThe International Journal of Bank Marketing, Vo1. 17, No. 1, pp. 5-19.

[2] Andreassen, T.W., Lindestad, B.(1998),"Customer loyalty and complex services" International Journal of Service Industry Management, Vol. 9 No.1, pp.7-23.

[3] Baker, M.J. (1993). Bank Marketing - Myth or Realit y?The International Journal ofBank Marketing, Vol. 11, No. 6.

[4] Barich, H., Kotler, P.(1991). A Framework for Marketing Image Management Sloan Management Review, Winter, pp. 94-104

[5] Beckett, A., Hewer, P., Howcroft, B. (2000). An Exposition of Consumer Behaviour inthe Financial Services Industry The International Journal of Bank Marketing,Vol. 18, No. 1, pp. $15-26$.

[6] Bitner, M.J. (1990). Evaluating Service Encounter: The Effects of Physical Surroundings and Employee Responses Journal of Marketing, Vol. 54, April, pp. 69-82.

[7] Bove, L.L., Johnson L.W. (2000). A Customer-service Worker Relationship Model International Journal of Service Industry Management, Vol. 11, No. 5, pp. 491-511.

[8] Boyd (1994). Consumer Selection Criteria For Banks In Poland, U.S.A.

[9] Butcher, K., Sparks, B., O'Callaghan, F (2001). Evaluative and Relational Influenceson

[10] Service Loyalty International Journal of Service Industry Management, Vol.12, No.3/4, pp. 310-328.

[11] Cadotte, E.R., Woodruff, R.B.,Jenkins, R.L. (1987), "Expectations and norms in models of consumer satisfaction", Journal of Marketing Research, Vol. 24 pp.305-14.

[12] Chang, Z.Y., Chan, J., Leck, S.L. (1997). Management of Market Quality forCorrespondentBanking Products. The International Journal of Bank Marketing,1997, Vol. 15, No. 1, pp. 32-35.

[13] Christopher, M., Payne,A., Ballantyne, D.(1991). Relationship Marketing - Bringing Quality, Customer Service and Marketing Together Oxford: Butterworth-Heinemann. CIM study text, Understanding Customers, 5th edition (1998), BPP Publishing Limited, UK.

[14] Clark, N., Peck, H., Payne, A., Christopher, M. (1995). Relationship Marketing: Towards a New Paradigm.In A. Payne (Ed.), Advances in Relationship Marketing- London.
[15] Colgate, M., Danaher, P. J. (2000). Implementing a Customer Relationship Strategy: The Asymmetric Impact of Poor Versus Excellent Execution Journal of the Academy of Marketing Science, Vol. 28, No. 3, Summer, pp. 375-387.

[16] Colgate, M., Norris, M. (2001). Developing a Comprehensive Picture of Service Failure International Journal of Service Industry Management, Vo1. 12, No. 3/4, pp. 215-235.

[17] Colgate, M., Stewart, K., Kinsella, R. (1996). Customer Defection: A Study of the Student Market in Ireland The International Journal of Bank Marketing, Vol. 14, No. 3,pp. 23-29.

[18] Cronin, J.J., Taylor, S.A. (1992) Measuring Service Quality: A Reexamination and Extension Journal of Marketing, Vol. 56, July, pp. 55-68.

[19] Czepiel, J.A, (1992).Competitive Marketing Strategy, Prentice-Hall, London.

[20] Daniell, A. (2000). The Myth of Cross-Selling American Banker, Vol. 165, No. 53,March, pp. 7.

[21] DiniHaryani , Customer Satisfaction Towards Customer Service, (2002), U.K

[22] Ennew, C.T., Binks, M.R. (1997). The Impact of Service Quality and ServiceCharacteristics on Customer Retention: Small Business and their Banks in the UKBritish Journal of Management, Vol. 7, pp. 219-230.

[23] Farquhar, J. (2004). Customer Retention in Retail Financial Services: An Employee Perspective International Journal of Bank Marketing, Vol. 22, No. 2/3, pp. 86-99.

[24] Fisher, A.(2001). Winning the Battle for Customers Journal of Financial Services Marketing, Vol. 6, No. 1, September, pp. 77-84.

[25] Gilmore, R., Czepiel, J.A. (1987).Reconceptualising Loyalty in Economic Exchange Relationships: Are Marketers People? unpublished working paper, GraduateSchool of Business Administration, New York University, NY.

[26] Hallowell, R. (1996), "The relationships of customer satisfaction, customer loyalty and profitability: an empirical study", International Journal of Service Industry Management, Vol. 7 No.4, pp.27-42.

[27] Holmlund, M., Kock, S. (1996), "Relationship marketing: the importance of customer-perceived service quality in retail banking", The Service Industries Journal, Vol.16 No.3, pp.287-304.

[28] Hull, L. (2002). Foreign-owned Banks: Implications for New Zealand's Financial Stability. Discussion Paper Series, DP2002/05.

[29] John C, (1995), Consumer Behavior, 4th edition Prentice Hall, UK.

[30] Kotler P, Marketing Management, 11th edition (2003), Pearson Education International, USA. Lee, j., Pi, S., Kwok, R. C., and Huynh, M. Q., 2003: "The Contribution of Commitment Value in Internet Commerce: An Empirical Investigation," Journal of the Association for Information Systems, Volume 4, , pp.39-64.

[31] McKechnie, M.(1992). Insights Into Buyer Behavior For Financial Services, National Library of Canada, Canada 
[32] Meriwether Lewis(1993). The Journals of Lewis, Nebraska Press, Canada

[33] Moutinho , Managing and Marketing Services In The 1990s, (1992), Dry Press, U.S.A Mugenda.O.\&Mugenda. A.(2003) Research Methods: Quantitative and Qualitative Approaches.Nairobi: Acts Press

[34] Oliver, R. L., and Swan, J. E., 1989: "Kenya Commercialand Disconfirmation Perceptionsas Influences on Merchant and Product Satisfaction,” Journal of Customer Research, Volume 16, Number 3, , pp.372-383.
[35] Philip Kotler(2006). Principles of Marketing, 11thedition. Pearson Prentice Hall, New Jersey, U.S.A

[36] Reichheld, F. F. (1996). Learning from Customer Defections. Harvard Business Review March/April,pp. 56-69.

[37] Zeithaml, V.A. (2000) 'Service quality, profitability, and the economic worth of customers: what we know and what we need to learn', Journal of the Academy ofMarketing Science, Vol. 28, No. 1, pp.67-85. 